Congruence between graduating nursing students' self-assessments and mentors' assessments of students' nurse competence

\title{
Kajander-Unkuri, Satu
}

2016

Kajander-Unkuri , S , Leino-Kilpi , H , Katajisto , J , Meretoja , R , Raisanen , A , Saarikoski , M , Salminen , L \& Suhonen , R 2016 , ' Congruence between graduating nursing students' self-assessments and mentors' assessments of students' nurse competence ', Collegian , vol. 23 , no. 3 , pp. 303-312 . https://doi.org/10.1016/j.colegn.2015.06.002

http://hdl.handle.net/10138/224641

https://doi.org/10.1016/j.colegn.2015.06.002

publishedVersion

Downloaded from Helda, University of Helsinki institutional repository.

This is an electronic reprint of the original article.

This reprint may differ from the original in pagination and typographic detail.

Please cite the original version. 


\title{
Congruence between graduating nursing students' self-assessments and mentors' assessments of students' nurse competence
}

\author{
Satu Kajander-Unkuri, PhD, RN ${ }^{a, b, *}$, \\ Helena Leino-Kilpi, PhD, RN, FEANS ${ }^{\text {a,c }}$, \\ Jouko Katajisto, MSocSci ${ }^{d}$, \\ Riitta Meretoja, PhD, RN ${ }^{\mathrm{a}, \mathrm{b}}$, Anu Räisänen, DHSc, MScNE, RN ${ }^{\mathrm{e}}$, \\ Mikko Saarikoski, PhD, RN ${ }^{a}$, Leena Salminen, $\mathrm{PhD}, \mathrm{RN}^{\mathrm{a}}$, \\ Riitta Suhonen, PhD, RN, FEANS ${ }^{a}$
}

\author{
a Department of Nursing Science, University of Turku, Finland \\ b Corporate Headquarters, Helsinki University Hospital, Finland \\ c Turku University Hospital, Finland \\ d Department of Mathematics and Statistics, University of Turku, Finland \\ e Finnish Education Evaluation Center, Finland
}

Received 29 May 2014; received in revised form 18 March 2015; accepted 11 June 2015

\section{KEYWORDS}

Graduating nursing student;

Nurse competence; Nurse education; Nursing skills; Self-assessment; Mentor

\begin{abstract}
Summary Self-assessment is widely used to assess competence in health care, although there is evidence of the weaknesses of self-assessment in the literature. In general, the process of self-assessment has been found to stimulate students' deep-level learning and problem-solving skills. Nursing students need to develop their self-assessment skills in order to identify their learning and ensure up-to-date outcomes and safe practice. This study aims to assess the congruence between graduating nursing students' self-assessment and their mentors' assessments concerning nurse competence with particular focus on nursing skills.

The data were collected in November-December 2011 in the last week of final clinical placement of nurse education. Completed questionnaires were received from 60 students and 50 mentors. From these, 42 student-mentor pairs were matched for the sample of this study. Descriptive and inferential statistics were used in the data analysis.

Comparisons between the assessments showed that students assessed their nurse competence as higher than their mentors (VAS $64.5 \pm 12.2$ vs. $56.7 \pm 19.0$ ). In nursing skills, the assessments were closer to each other (VAS $75.4 \pm 12.8$ vs. $72.2 \pm 16.7$ ); however, students' assessments still remained higher than those of mentors'. No congruent assessments were found between students and mentors.
\end{abstract}

\footnotetext{
* Corresponding author at: University of Turku, Department of Nursing Science, FI-20014 University of Turku, Finland. Tel.: +358 405152774. E-mail address: satu_kajander@hotmail.com (S. Kajander-Unkuri).
} 
Compared to mentors' assessments, students overestimated their nurse competence. However, the results may be due to different understanding of nurse competence, and more research is needed on students' self-assessment by comparing students' assessments with those of peers, mentors and/or educators or knowledge tests. Nursing students should practise self-assessment during their nurse education. Mentors would also benefit practising in assessing students' nurse competence.

(c) 2015 Australian College of Nursing Ltd. Published by Elsevier Ltd.

\section{Introduction}

The transition process from student to professional nurse can be challenging and stressful for a new nurse (Duchscher, 2008, 2009; Yong, Stuenkel, \& Bawel-Brinkley, 2008), competence being one of the factors affecting this transition (Yeh \& Yu, 2009). The assessment of the nurse competence of graduating nursing students (hereafter students) is critical for identifying areas of educational and developmental needs. Assessing the nurse competence of students provides information about students' learning outcomes for educational evaluation and improvement (Marshburn, Engelke, \& Swanson, 2009) and also has implications for retention and patient safety (Meretoja, Isoaho, \& Leino-Kilpi, 2004).

Self-assessment is widely used to assess nurse competence in the clinical context (Bing-Jonsson, Bjørk, Hofoss, Kirkevold, \& Foss, 2013; Watson, Stimpson, Topping, \& Porock, 2002; Yanhua \& Watson, 2011). However, relatively recent studies indicate that there may be discrepancy between self-assessment and observed performance (Baxter \& Norman, 2011; Lauder et al., 2008). Nursing is not alone in this, as similar results have been found, for example, among practising physicians (Davis et al., 2006) and medical students (Blanch-Hartigan, 2011). However, self-assessment has been considered an important aspect of a multi-method assessment strategy (Norman, Watson, Murrels, Calman, \& Redfern, 2002). Self-assessment is also recommended, for example, by the registration board in Australia to review feedback from patients and to confirm competence to practice (Nursing and Midwifery Board of Australia, 2010).

In this study, nurse competence (hereafter competence) is seen as an outcome of general nursing education, referring to "functional adequacy and the capacity to integrated knowledge, skills, attitudes and values in specific contextual situations of practice"' (Meretoja, Leino-Kilpi, \& Kaira, 2004, pp. 330-331). Nursing skills are the foundation of competence, with scientific knowledge and moral development (Epstein \& Hundert, 2002). In this study, nursing skills are defined as unique activities requiring knowledge to plan, carry out and assess accurate nursing actions in patient care. The nursing skills assessed in this study are nursing skills related to body temperature regulation, infection prevention, control (IP\&C) and patient hygiene, oxygenation and respiration, medication administration, pain management, cardiovascular circulation, sleep, rest and exercise, fluid balance, urinary and bowel elimination (FU\&B) and nutrition and care of a dying patient.

This paper reports findings from a study conducted in Finland where students' competence with particular focus on nursing skills was evaluated at the point of graduation. The nurse education (Bachelor's degree, 3.5 years) is carried out in polytechnics in Finnish or in Swedish (21 and 2, respectively). The education leads to the qualification of general registered nurse without any specialisation. The Bachelor's degree requires 210 ECTS (European Credit Transfer and Accumulation System) and the content of nurse education is based on European Union directive 2005/36/EC (European Commission, 2005; Ministry of Education, 2010, 2011). The Directive 2005/36/EC defines the length and minimum content (theoretical and clinical training) of nurse education in the European Union (EU), but at the time of this study, there was no common definition of the competence level of nursing students required upon degree completion (European Commission, 2005). The modernised Directive (2013/55/EU) was published in 2013 and some changes were made to the content of nurse education. In addition, eight common competencies for nurses responsible for general care are now mentioned in Article 31. EU Member States now have two years to transpose the Directive into national law, and nursing students qualifying after 2016 should meet these competencies (European Commission, 2013). The regulatory body in Finland, the National Supervisory Authority for Welfare and Health (Valvira), does not have specific requirements for nurses. The licence to practise as a nurse in Finland is granted, upon application, based on the diploma (Valvira, 2014).

We assessed the congruence between students' selfassessments and their mentors' assessments in the last week of final clinical placement of nurse education. Assessing the congruence between the two assessments is important as self-assessment is widely used in clinical practice, but the literature related to the congruence between selfassessments and assessments by another party is scarce. The study also improves knowledge in the field of student assessment in clinical practice.

\section{Background}

Nurses work in the dynamic field of health care, where major changes are taking place around the world (Auerbach, Staiger, Muench, \& Buerhaus, 2013). These changes pose challenges to nurses' competences, which need to be frequently refreshed (Bahn, 2007; O’Shea, 2003). After nurse education and graduation, nurses have to be responsible for their own continuing training during their career ( 0 'Shea, 2003). This is known as lifelong learning, which is linked to self-directed learning (Levett-Jones, 2005; O'Shea, 2003). In self-directed learning, individuals recognise their learning needs, set goals, and after implementing suitable learning strategies, self-assess the achieved results (Knowles, Holton, \& Swanson, 2008). Thus, self-assessment is a 
necessary skill for lifelong learning (Dearnley \& Meddings, 2007; Galbraith, Hawkins, \& Holmboe, 2008), which is one of the strategic objectives of the new European strategic framework for the Education and Training 2020 programme (Council of the European Union, 2009). In Europe, one challenge is to ensure an adequate workforce of health professionals in the health care system (WHO, 2009). This calls for putting nurses' competencies to their optimal use as the number of nurses is not adequate to meet current and projected future needs (WHO, 2014). A well-educated and skilled nursing workforce is essential to the provision of safe and effective health care. This justifies the evaluation of self-assessment in students' competence assessment as nurses who cannot accurately self-assess themselves may be at greater risk of providing suboptimal care to patients.

Self-assessment is defined as a process of self-directed assessment initiated and driven by the individual and is used for lifelong learning, where one's weaknesses and strengths are identified (Eva \& Regehr, 2005). Self-assessment has been identified as "a process by which a student undertakes the task of looking outward to seek feedback and explicit information from external sources and uses these externally generated sources of assessment data to direct performance improvement"' (Eva \& Regehr, 2008, p. 15). The self-assessment process requires skills in identifying self-ability in comparison to the required standards for a task and skills in seeking and using constructive feedback (Dearnley \& Meddings, 2007). Self-assessment also encourages students' metacognition and is effective in encouraging deep-level learning instead of surface-level learning as it increases reflection of student's own work (Brown, 2004) and promotes dialogue between students and teachers (Dearnley \& Meddings, 2007).

The concept of competence is widely discussed in nursing, but a common understanding or definition has still not been agreed upon. The term competence refers to a state of being or a quality. It is a holistic term that refers to one's overall capacity or ability to do something successfully (ten Cate \& Scheele, 2007). Three main approaches to conceptualising competence can be found in the literature: (1) behaviouristic; a task- and skill-based approach, (2) generic; focus on transferable attributes and (3) holistic; brings together knowledge, skills, attitudes and values. (Cowan, Norman, \& Coopamah, 2005; Garside \& Nhemachena, 2013; Gonczi, 1994; Watson et al., 2002). In this study, a holistic approach (Cowan et al., 2005; Garside \& Nhemachena, 2013; Gonczi, 1994; Watson et al., 2002) to competence was adopted. It refers to expected level of knowledge, nursing skills, values and attitudes of the graduating nursing student and can be transferred between nursing contexts.

The assessment of competence has been found difficult in the literature and various methods and instruments have been developed. The most common methods are structured or non-structured instruments based on self-assessment (Bing-Jonsson et al., 2013; Watson et al., 2002; Yanhua \& Watson, 2011). Self-assessment has been found to be an important element of a multi-method assessment strategy (Cowan et al., 2005; Norman et al., 2002), where different assessment methods are used in a combined approach to assess competence, as there is no golden standard for assessing competence (Watson et al., 2002). Self-assessment is also considered a timesaving and cost-effective method
(Cowan, Wilson-Barnett, Norman, \& Murrels, 2008). Lauder et al. (2008) have stated that in a clinical context, competence assessment requires student's competence to be assessed by someone else than the student.

Previous nursing studies have reported contradictory results between self-assessment and assessment of students' competence by qualified nurses (Löfmark, Smide, \& Wikblad, 2006), mentors (Bartlett, Simonite, Westcott, \& Taylor, 2000), line-managers (Clinton, Murrels, \& Robinson, 2005) or nurse experts (Raines, 2010). Typically, the differences between these two assessments were studied comparing the assessments at group level by statistical test of group means, and the association of the two assessments was not reported (Bartlett et al., 2000; Clinton et al., 2005; Löfmark et al., 2006; Raines, 2010). Competence studies where students' self-assessment is compared with assessment by another party at single level (matched pairs) are lacking in the nursing literature.

\section{The study}

\subsection{Aim}

The aim of this study was to assess the congruence between students' self-assessments and their mentors' assessments of competence with particular focus on nursing skills at the point of graduation. The study improves knowledge in the field of student assessment in clinical practice. The research questions were:

(1) What is the congruence between students' selfassessments and their mentors' assessments of students' competence?

(2) What is the congruence between students' selfassessments and their mentors' assessments of students' nursing skills?

\subsection{Design}

The study employed a comparative survey design using a structured questionnaire among students and their mentors. In this study, mentor refers to a registered nurse who facilitates learning and supervises students in the clinical placement.

\subsection{Setting, data collection and sample}

Approximately 2200 nursing students graduate each year in Finland (Ministry of Education and Culture, 2012), and approximately 400 of them have their final clinical placement in different units and wards in university hospitals. The target population in this study comprised students practising in their final clinical placements in medical, surgical or paediatric wards in university hospitals in Finland and their mentors. Polytechnics $(n=14)$ with representative geographical locations in Finland were selected for the study with four university hospitals (out of five) based on their mutual similarities with bed number, staff number and treatment periods (National Institute for Health and Welfare, 2012), as well with wide geographical locations. 
Data were collected in November-December 2011. Based on the information from the contact teachers at each polytechnic there were 65 students practising in medical, surgical or paediatric wards in these university hospitals; all these students were invited to the study. Information about the study, with the Internet link of the questionnaire, was sent to the students by e-mail by the contact teachers. The mentors were contacted with the help of the contact nurses either by e-mail or personally at specially arranged sessions. The questionnaire was delivered to the mentors, who gave their consent $(N=51)$ with an envelope addressed to the researcher. There was a code number in the mentor's questionnaire given to the student, who entered it on the on-line questionnaire to match the evaluations in the data analysis. Completed questionnaires were received from 60 students (response rate $92.3 \%$ ) and from 50 mentors (98.0\%). Of these, 42 student-mentor pairs were matched for the sample of this study.

\subsection{Questionnaire}

The questionnaire consisted of two previously validated instruments and socio-demographic variables. For measuring competence, the generic Nurse Competence Scale (NCS; Meretoja, Isoaho, et al., 2004) was used. The NCS was originally developed for practising nurses to assess nurse competence with 73 items in seven competence categories (Meretoja, Isoaho, et al., 2004). The instrument has also been used for newly graduated nurses (up to 10 months after graduation) (Hengstberger-Sims et al., 2008; Lima, Newall, Kinney, Jordan, \& Hamilton, 2014; Wangensteen, Johansson, Björkström, \& Nordström, 2012) and graduating nursing students at the point of graduation (Kajander-Unkuri, Meretoja, et al., 2014). The psychometric properties of the NCS have been tested internationally and it has been proved to be valid, reliable and sensitive to measure nurse competence at the generic level in different clinical care contexts and in a wide range of work experience (Meretoja, Isoaho, et al., 2004; Hengstberger-Sims et al., 2008; Istomina et al., 2011; Wangensteen et al., 2012; Kajander-Unkuri, Meretoja, et al., 2014). The content validity of the NCS has been confirmed by assessments by international expert panels and pilot tests (Istomina et al., 2011; Meretoja, Isoaho, et al., 2004) and by using the NCS in different cultural and environmental settings with practising nurses (Istomina et al., 2011; Meretoja, Isoaho, et al., 2004; Numminen, Meretoja, Ihoaho, \& Leino-Kilpi, 2013). The reliability of the NCS has been estimated by alpha-if-deleted values and determination of correlations. In the analyses, the Cronbach's alpha coefficient for the NCS categories has ranged from 0.78 to 0.96 with practising nurses (Istomina et al., 2011; Meretoja, Isoaho, et al., 2004; Numminen et al., 2013) and from 0.61 to 0.96 with newly graduated nurses. (Hengstberger-Sims et al., 2008; Lima et al., 2014; Wangensteen et al., 2012) and from 0.84 to 0.93 with graduating nursing students at the point of graduation (Kajander-Unkuri, Meretoja, et al., 2014).

For measuring nursing skills, the mHOTOHA (HOTOHA; Hoitotoimintojen hallinta; Command of nursing functions; Räisänen, 2002) was used. The HOTOHA was designed to assess a person's command of the functions of nursing. The modification of the instrument is reported elsewhere. The mHOTOHA consists of 92 items in nine nursing skills categories. The content validity of the original HOTOHA has been assessed as high by careful operationalisation of the concepts used in the HOTOHA and by a multi-item instrument. The content validity was also confirmed by assessments by an expert panel (Räisänen, 2002). The content validity of mHOTOHA has been assessed by expert panel and a pilot study. The construct validity of mHOTOHA has been tested and found to be good (Kajander-Unkuri, Suhonen, et al., 2014). The reliability of the original HOTOHA categories has been estimated by determination of correlations and alphaif-deleted values. In the analysis, the Cronbach's alpha coefficient for the original HOTOHA categories ranged from 0.87 to 0.96 with graduating nursing students (Räisänen, 2002). The Cronbach's alpha coefficient for the mHOTOHA categories ranged from 0.87 to 0.94 with graduating nursing students at the point of graduation (Kajander-Unkuri, Suhonen, et al., 2014). All items were rated using a Visual Analogue Scale (VAS; 0-100), with the end labelled 0 for very low and the end labelled 100 for very high level of competence/nursing skills. For the content, see Table 1.

\subsection{Ethics of the study}

The Ethics Committee of the University of Turku gave ethical approval for the study, while study permissions were given by each polytechnic participating in the study $(n=14)$ and the administrations of the four university hospitals. All data were handled anonymously. Respondents agreed to participate after receiving written information about the study. All information was processed confidentially (Pauwels, 2007). Permissions to use the Finnish version of the NCS and to use and modify the HOTOHA were received from the copyright holders.

\subsection{Data analysis}

Data analysis was performed by using SPSS 19 (SPSS Inc., Chicago, USA) software. Mean values and standard deviations were used to describe socio-demographics and variables of competence and nursing skills. Altogether 16 sum variables were formed. The mean VAS values of the categories were calculated by adding the item scores in each category and dividing the sum by the number of answers. Differences between VAS mean scores for the two groups, students and mentors, were tested by paired samples $t$-test. Normality of differences was tested with Shapiro-Wilk tests and distribution of differences did not statistically deviate from normal distribution. Dependence between the two groups was analysed with Spearman's correlation coefficient. Correlation coefficients $>0.3$ indicated at least moderate dependence of assessments. Frequencies and percentages were used to analyse the congruence of the assessments of single student-mentor pairs. Discriminant analysis was used to evaluate which categories of the questionnaire were most important to describe the difference between students and mentors. The $p$-value $\leq 0.05$ was regarded significant. The internal consistency of the NCS and mHOTOHA categories was analysed by using Cronbach's alpha coefficient. For the NCS it ranged from 0.81 
Table 1 Student and mentor assessments of competence with particular focus on nursing skills at group level and correlation coefficients for pair assessments.

\begin{tabular}{|c|c|c|c|c|c|c|c|c|c|c|c|c|c|c|}
\hline & \multicolumn{5}{|c|}{ Students } & \multicolumn{5}{|c|}{ Mentor } & \multirow[t]{2}{*}{ Difference } & \multirow[t]{2}{*}{$p^{*}$} & \multirow[t]{2}{*}{$r$} & \multirow[t]{2}{*}{$p$} \\
\hline & Mean & SD & Min & Max & $\alpha$ & Mean & SD & Min & Max & $\alpha$ & & & & \\
\hline \multicolumn{15}{|c|}{ Competence categories (NCS) } \\
\hline Helping role & 77.2 & 8.9 & 18.8 & 95.7 & 0.81 & 63.4 & 16.7 & 17.1 & 98.6 & 0.87 & 13.8 & $<0.001$ & 0.192 & ns \\
\hline Diagnostic functions & 70.9 & 13.1 & 14.3 & 100.0 & 0.84 & 55.4 & 23.1 & 5.7 & 95.7 & 0.94 & 15.5 & 0.001 & -0.076 & ns \\
\hline Teaching-coaching & 68.0 & 13.8 & 21.3 & 96.3 & 0.93 & 59.0 & 18.8 & 16.3 & 96.9 & 0.97 & 9.0 & 0.011 & 0.125 & ns \\
\hline Ensuring quality & 66.0 & 15.4 & 5.0 & 100.0 & 0.82 & 55.3 & 23.1 & 5.0 & 98.3 & 0.91 & 10.7 & 0.009 & 0.188 & ns \\
\hline Managing situations & 62.5 & 15.8 & 0.0 & 100.0 & 0.89 & 56.2 & 23.2 & 5.7 & 96.3 & 0.96 & 6.3 & ns & 0.272 & ns \\
\hline Work role & 59.7 & 15.2 & 6.3 & 93.7 & 0.92 & 57.5 & 21.2 & 17.4 & 100.0 & 0.96 & 2.2 & ns & 0.147 & ns \\
\hline $\begin{array}{l}\text { Therapeutic } \\
\text { interventions }\end{array}$ & 58.8 & 16.2 & 3.0 & 98.0 & 0.91 & 49.7 & 21.8 & 4.0 & 93.0 & 0.95 & 9.1 & 0.020 & 0.208 & ns \\
\hline Total & 64.5 & 12.2 & & & & 56.7 & 19.0 & & & & 8.3 & 0.013 & 0.179 & ns \\
\hline \multicolumn{15}{|c|}{ Nursing skills categories (тНОТОНА) } \\
\hline $\begin{array}{l}\text { Infection prevention, } \\
\text { control and patient } \\
\text { hygiene }\end{array}$ & 81.4 & 7.2 & 32.0 & 97.0 & 0.86 & 78.6 & 16.7 & 31.8 & 100.0 & 0.97 & 2.8 & ns & -0.097 & ns \\
\hline $\begin{array}{l}\text { Body temperature } \\
\text { regulation }\end{array}$ & 81.2 & 8.9 & 20.0 & 100.0 & 0.85 & 78.0 & 16.4 & 36.0 & 100.0 & 0.92 & 3.2 & ns & -0.036 & ns \\
\hline Pain management & 77.4 & 8.1 & 39.0 & 98.0 & 0.90 & 73.1 & 16.8 & 23.0 & 99.0 & 0.94 & 4.3 & ns & 0.034 & ns \\
\hline $\begin{array}{l}\text { Medication } \\
\text { administration }\end{array}$ & 77.2 & 8.9 & 31.8 & 100.0 & 0.89 & 76.5 & 19.2 & 16.4 & 100.0 & 0.96 & 0.7 & ns & 0.278 & ns \\
\hline $\begin{array}{l}\text { Oxygenation and } \\
\text { respiration }\end{array}$ & 76.6 & 10.2 & 13.8 & 100.0 & 0.91 & 72.0 & 20.2 & 30.0 & 100.0 & 0.94 & 2.2 & ns & 0.029 & ns \\
\hline Sleep, rest and exercise & 75.6 & 9.1 & 22.2 & 97.8 & 0.89 & 73.4 & 17.1 & 15.6 & 100.0 & 0.95 & 2.2 & ns & 0.143 & ns \\
\hline $\begin{array}{l}\text { Fluid balance, urinary } \\
\text { and bowel elimination } \\
\text { and nutrition }\end{array}$ & 74.5 & 9.6 & 25.9 & 100.0 & 0.91 & 69.5 & 18.4 & 27.6 & 98.2 & 0.97 & 5.0 & ns & 0.367 & 0.017 \\
\hline $\begin{array}{l}\text { Cardiovascular } \\
\text { circulation }\end{array}$ & 72.1 & 10.7 & 17.9 & 100.0 & 0.93 & 68.0 & 19.5 & 20.0 & 98.3 & 0.94 & 4.1 & ns & 0.282 & ns \\
\hline Care of a dying patient & 64.1 & 15.1 & 7.1 & 100.0 & 0.87 & 65.6 & 21.6 & 4.3 & 100.0 & 0.93 & -1.5 & ns & 0.031 & ns \\
\hline Total & 75.4 & 12.8 & & & & 72.2 & 16.7 & & & & 3.2 & ns & 0.203 & ns \\
\hline
\end{tabular}

ns = not significant.

* Paired samples $t$-test. 
Table 2 Congruence between student's and mentor's assessments at single student - mentor level $(n=42)$.

\begin{tabular}{|c|c|c|c|c|c|c|}
\hline & \multicolumn{2}{|c|}{$\begin{array}{l}\text { Student's assessment } \\
\text { higher }\end{array}$} & \multicolumn{2}{|c|}{ Congruent assessment } & \multicolumn{2}{|c|}{$\begin{array}{l}\text { Mentor's assessment } \\
\text { higher }\end{array}$} \\
\hline & $f$ & $\%$ & $f$ & $\%$ & $f$ & $\%$ \\
\hline Competence (NCS) $(n=41)$ & 28 & 68.3 & 0 & 0 & 13 & 31.7 \\
\hline Helping role & 33 & 78.6 & 2 & 4.8 & 7 & 16.6 \\
\hline Diagnostic functions $(n=41)$ & 30 & 73.2 & 1 & 2.4 & 10 & 24.4 \\
\hline Teaching-coaching & 29 & 69.0 & 0 & 0 & 13 & 31.0 \\
\hline Ensuring quality & 31 & 73.8 & 1 & 2.4 & 10 & 23.8 \\
\hline Managing situations & 26 & 61.9 & 0 & 0 & 16 & 38.1 \\
\hline Work role & 25 & 59.5 & 0 & 0 & 17 & 40.5 \\
\hline Therapeutic interventions & 26 & 61.9 & 3 & 7.1 & 13 & 31.0 \\
\hline $\begin{array}{l}\text { Nursing skills (mHOTOHA) } \\
\quad(n=41)\end{array}$ & 25 & 61.0 & 0 & 0 & 16 & 39.0 \\
\hline $\begin{array}{l}\text { Infection prevention, control } \\
\text { and patient hygiene }\end{array}$ & 22 & 52.4 & 1 & 2.4 & 19 & 45.2 \\
\hline Body temperature regulation & 21 & 50.0 & 2 & 4.8 & 19 & 45.2 \\
\hline Pain management & 27 & 64.3 & 0 & 0 & 15 & 35.7 \\
\hline Medication administration & 19 & 45.2 & 0 & 0 & 23 & 54.8 \\
\hline $\begin{array}{l}\text { Oxygenation and respiration } \\
\quad(n=41)\end{array}$ & 22 & 53.7 & 2 & 4.8 & 17 & 41.5 \\
\hline Sleep, rest and exercise & 20 & 47.6 & 1 & 2.4 & 21 & 50.0 \\
\hline $\begin{array}{l}\text { Fluid balance, urinary and } \\
\text { bowel elimination and } \\
\text { nutrition }\end{array}$ & 23 & 54.8 & 1 & 2.4 & 18 & 42.8 \\
\hline Cardiovascular circulation & 21 & 50.0 & 2 & 4.8 & 19 & 45.2 \\
\hline Care of a dying patient & 22 & 52.4 & 2 & 4.8 & 18 & 42.8 \\
\hline
\end{tabular}

to 0.93 (students) and from 0.87 to 0.97 (mentors) and for mHOTOHA from 0.85 to 0.93 (students) and from 0.92 to 0.97 (mentors). There were missing data in two mentors' questionnaires (categories of diagnostic function and oxygenation and respiration), so the means of these categories and total score of competence and nursing skills have been calculated from the assessments of 41 mentors.

\section{Results}

The typical student respondent was a 25.5-year-old (range 21-40 years) female, who had no previous professional qualifications, had been working in health care during semesters and was graduating to her first choice of profession. The typical mentor respondent was a 39-year-old (range 25-59) female, who had been working in health care on average 14.5 years (range $1.5-32$ ), of which 10 years in the current ward. The typical mentor had been supervising nursing students for almost 12 years and supervised on average four nursing students per year.

The congruence between students' self-assessments and their mentors' assessments of students' competence was evaluated comparing the assessments at group level by statistical test of group means and comparing the assessments at single student-mentor level. In the evaluation at group level, students assessed themselves to have higher competence than assessed by their mentors (64.5 \pm 12.2 vs.
$56.7 \pm 19.0$, mean $\pm S D, p=0.013$ ). In five categories (out of seven) the difference between the two assessments was statistically significant. Students, as well as their mentors, assessed their competence to be highest in the category of helping role and the lowest in the category of therapeutic interventions. The correlation coefficients for student and mentor paired assessments were generally low and no statistically significant correlations were found (Table 1).

In the evaluation at single student-mentor level concerning competence, no congruent assessments were found. More than two-thirds (68.3\%) of the students assessed their competence higher than their mentors. A few congruent assessments were found in the categories of therapeutic interventions, helping role, diagnostic functions and ensuring quality (Table 2). However, if $5 \%$ and $10 \%$ difference margin is accepted, $8(19 \%)$ and $13(31.7 \%)$ congruent assessments were found, respectively (Fig. 1).

The congruence between students' self-assessments and their mentors' assessments of students' nursing skills was evaluated comparing the assessments at group level by statistical test of group means and comparing the assessments at single student-mentor level. In the evaluation at group level, students' assessments were close to mentors' assessments $(75.4 \pm 12.8$ vs. $72.2 \pm 16.7)$. Compared to their mentors, students assessed their nursing skills higher in every category bar one (care of a dying patient). Students, as well as their mentors, assessed their nursing skills to be highest in the category of infection prevention, 


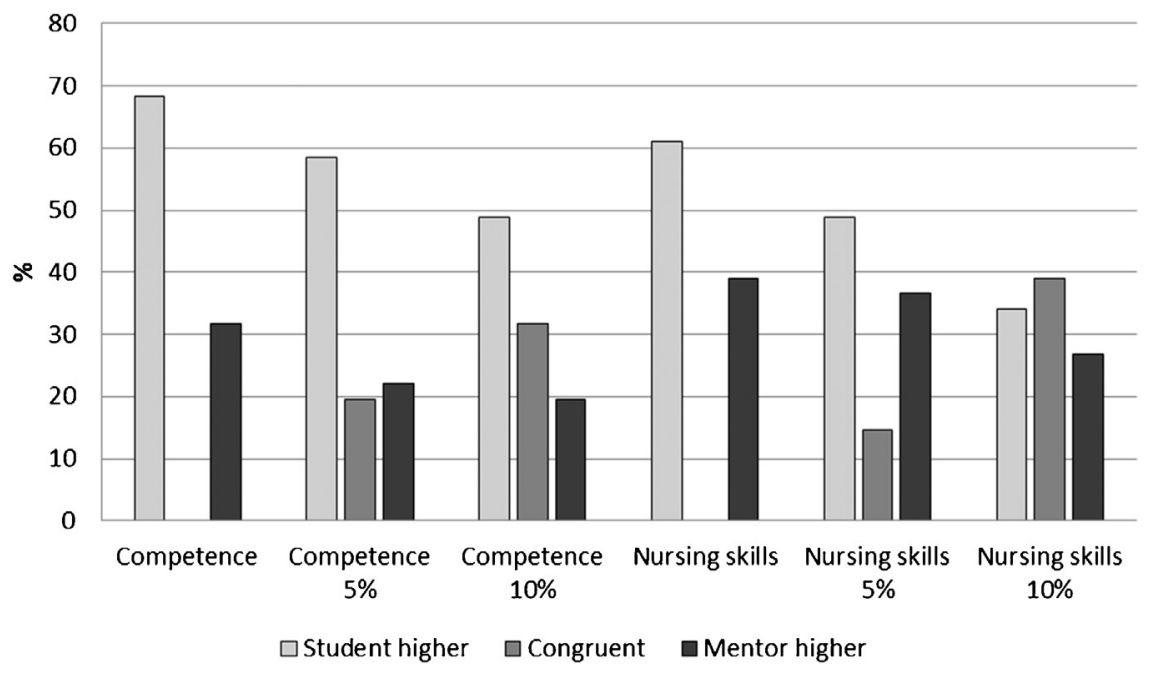

Figure 1 Percentage of congruent assessments at single student-mentor level and with 5\% and 10\% difference margins.

control and patient hygiene and the lowest in care of a dying patient. The correlation coefficients for student and mentor paired assessments were low: only one statistically significantly correlation was found (Table 1).

In the evaluation at single student-mentor level concerning nursing skills, no congruent assessments were found. Sixty-one per cent of the students assessed their nursing skills higher than their mentors. A few congruent assessments were found in all but two categories (pain management and medication administration) (Table 2). However, if $5 \%$ and $10 \%$ difference margin is accepted, 6 (14.6\%) and $16(39.0 \%)$ congruent assessments were found, respectively (Fig. 1).

\section{Discussion}

Assessing the congruence between the two assessments is important as self-assessment is widely used in clinical practice, but the literature related to the congruence between self-assessment and assessment by another party is scarce. As nurses are responsible for their lifelong learning after nurse education, they need to be selfdirected learners; for this, they need self-assessment skills (Levett-Jones, 2005; O'Shea, 2003) in order to keep upto-date and for safe practice of nursing. Our data showed fairly large dissimilarities between students' and mentors' assessments of competence both at group level and at single student-mentor level. Inconsistency between the two assessments was also found in earlier studies (Löfmark et al., 2006; Raines, 2010), but in these studies the conclusions were made by comparing the assessments at group level by statistical test of group means. However, the assessments were mainly in line with each other, indicating similar opinions about areas in which students are good and in which they need to improve their performance. This finding also adds to the validity of the study. In the investigation of single student-mentor pairs concerning competence, no congruent assessments were found, but if we accepted a difference margin of $5-10 \%$, a few congruent assessments were found; however, students' assessments still remained higher than mentors'. Concerning nursing skills, the two assessments were closer to each other at group level, although only one statistically significant positive correlation was found. When looking at nursing skills at single student-mentor level, no congruent assessments were found, but if we accepted a $10 \%$ difference margin, congruent assessments made up the majority.

The difference between the two assessments concerning competence may be due to different understanding of competence. Assessing competence requires abstract thinking and understanding of nurses' responsibilities and work role. According to a previous study (Wangensteen, Johansson, \& Nordström, 2008; see also Ramritu \& Barnard, 2001), awareness of responsibility has been found as the most prominent difference between students and nurses, and students may not know what they need to know in order to be assessed as competent. It may be that in nurse education, skill-based learning has been emphasised more than competence as a holistic approach where knowledge, skills, attitudes and values meet the needs of a variety of clinical situations. The difference may also be due to a different reference point in relation to required competence. Mentors' assessments may be based on competence that a new nurse should achieve to succeed in clinical practice or on what is expected in their particular clinical area. It should also be remembered that in university hospitals, nursing care is highly specialised, and mentors' assessments may suggest that a high level of competence is required in these particular wards (see also Numminen et al., 2013). It may also be that the structure and emphasis of clinical placements teaches learning nursing skills instead of creating a holistic general view of nursing and its different dimensions. As curricula are changing to be more competence-based, it may influence competence assessment.

The results of this study indicate that compared to mentors' assessments, students overestimate their competence (see also Lakanmaa et al., 2014), but there can be problems in mentors' assessments as well, as indicated in earlier studies (Cassidy, 2009; Duffy, 2003). Both groups may benefit from assessment practise. The practise of students could include the educational benefits of self-assessment and the difficulties related to self-assessment, and the 
benefits of competence development by using self-assessment. Particular attention should be paid to the competence assessment process. During nurse education, students should receive plenty of opportunities for practising their self-assessment skills and receive realistic and constructive feedback from teachers and mentors. Self-assessment could also be combined with a more objective measurement of competence, for example a knowledge test or observation. This would help students to gain a realistic perception of their own performance, which is an important requirement for practising nurses. The practise of mentors could include the nursing curriculum, competence requirements for general nurses in Europe and practice in giving realistic and constructive feedback. This would ensure that the assessments are based on the criteria set.

\subsection{Strengths and limitations}

The strength of this study is comparing the two assessments at single student-mentor level, which is a new starting point as in earlier studies comparison has been made at group level by statistical test of group means. Some limitations can, however, be identified in the study. First, the NCS has been developed and mainly tested with practising nurses (Meretoja, Isoaho, et al., 2004; Meretoja, LeinoKilpi, et al., 2004; Numminen et al., 2013). There are also studies with newly graduated nurses (Hengstberger-Sims et al., 2008; Lima et al., 2014; Wangensteen et al., 2012). As for reliability, internal consistency among competence categories varied from 0.81 to 0.93 (students) and from 0.87 to 0.97 (mentors). The values are in line with other studies (Hengstberger-Sims et al., 2008; Kajander-Unkuri, Meretoja, et al., 2014; Wangensteen et al., 2012). Students and mentors used the whole scale (VAS 0-100) when making their assessments (Table 1), adding to the validity of the study. In addition, the NCS was suitable for measuring these two groups based on the discriminant analysis, where all but one category (work role) were important to describe the difference between students and mentors. Secondly, the empirical data came from Finnish students and their mentors working in university hospitals. It is noteworthy that cultural and environmental differences always introduce some limitations to generalising empirical findings internationally.

\section{Conclusion}

The results of this study suggest that competence assessment is a complex issue. As curricula are competence-based and self-assessment is used to assess nursing students' competence, it is important to develop self-assessment skills, and instruments for doing so should be incorporated into nurse education. Mentors would also benefit from practising in assessing students' competence. More collaboration between nurse education and practice is needed to reach a consensus about the required competence level and to find measures for developing competence from the beginning of nurse education. Future studies comparing the assessments of students to observations by peers, mentors and/or educators or knowledge tests could provide a wider picture of the competence and students' self-assessment.

\section{Authors contributions}

The Study Design was done by SK-U, HL-K, and RS. Data collection and analysis by SK-U and JK and the manuscript preparation by SK-U, HL-K, JK, RM, AR, MS, LS, and RS.

\section{Conflict of interest}

The authors state there is no conflict of interest.

\section{Acknowledgements}

We would like to thank all the graduating nursing students and mentors who participated in this study and the contact teachers in all polytechnics and contact nurses in the university hospitals in Finland who kindly helped with the data collection. We would also like to thank Anna Vuolteenaho for her expertise with the English language. The study was supported by the Finnish Nurses Association and Tehy (Union of Health and Social Care Professionals) and the Finnish Work Environment Fund, which are gratefully acknowledged.

\section{References}

Auerbach, D. I., Staiger, D. O., Muench, U., \& Buerhaus, P. I. (2013). The nursing workforce in an era of health care reform. New England Journal of Medicine, 368, 1470-1472.

Bahn, D. (2007). Orientation of nurses towards formal and informal learning: Motives and perceptions. Nurse Education Today, 27(7), 723-730.

Bartlett, H. P., Simonite, V., Westcott, E., \& Taylor, H. R. (2000). A comparison of the nursing competence of graduates and diplomats from UK nursing programmes. Journal of Clinical Nursing, 9(3), 369-381.

Baxter, P., \& Norman, G. (2011). Self-assessment or self deception? A lack of association between nursing students' self-assessment and performance. Journal of Advanced Nursing, 67(11), 2406-2413.

Bing-Jonsson, P. C., Bjørk, I. T., Hofoss, D., Kirkevold, M., \& Foss, C. (2013). Instruments measuring nursing staff competence in community health care: A systematic literature review. Home Health Care Management \& Practice, 25(6), 282-294.

Blanch-Hartigan, D. (2011). Medical students' self-assessment of performance: Results from three meta-analyses. Patient Education and Counseling, 84(1), 3-9.

Brown, S. (2004). Assessment for learning. Learning and Teaching in Higher Education 2004-2005, (1), 81-89.

Cassidy, S. (2009). Interpretation of competence in student assessment. Nursing Standard, 23(18), 39-46.

Clinton, M., Murrels, T., \& Robinson, S. (2005). Assessing competency in nursing: a comparison of nurses prepared through degree and diploma programmes. Journal of Clinical Nursing, 14(1), 82-94.

Council of the European Union. (2009). Education and Training 2020 (ET 2020). Retrieved from: http://eur-lex.europa.eu/ legal-content/en/txt/html/?uri=celex:52009xg0528(01)\&from= en

Cowan, D. T., Norman, I. J., \& Coopamah, V. P. (2005). Competence in nursing practice: A controversial concept: a focused review of literature. Nurse Education Today, 25(5), 355-362.

Cowan, D. T., Wilson-Barnett, D. J., Norman, I. J., \& Murrels, T. (2008). Measuring nursing competence: Development of a self-assessment tool for general nurses across Europe. International Journal of Nursing Studies, 45(6), 902-913. 
Davis, D. A., Mazmanian, P. E., Fordis, M., Van, H. R., Thorpe, K. E., \& Perrier, L. (2006). Accuracy of physician self-assessment compared with observed measures of competence: A systematic review. The Journal of the American Medical Association, 296(9), 1094-1102.

Dearnley, C. A., \& Meddings, F. S. (2007). Student self-assessment and its impact on learning - A pilot study. Nurse Education Today, 27(4), 333-340.

Duchscher, J. B. (2008). A process of becoming: The stages of new nursing graduate professional role transition. Journal of Continuing Education in Nursing, 39(10), 441-450.

Duchscher, J. B. (2009). Transition shock: The initial stage of role adaptation for newly graduated registered nurses. Journal of Advanced Nursing, 65(5), 1103-1113.

Duffy, K. (2003). Failing students: A qualitative study of factors that influence the decisions regarding assessment of students' competence in practice. Glasgow Caledonian University.

Epstein, R. M., \& Hundert, E. M. (2002). Defining and assessing professional competence. The Journal of the American Medical Association, 287(2), 226-235.

European Commission. (2005). Directive 2005/36/EC. Official Journal of the European Union, 30.9.2005. Retrieved from: http: / / www.nepes.eu/files/Directive\%202036\%20Recognition\% 20of\%20professional\%20qualification\%20EN.pdf

European Commission. (2013). Directive 2013/55/EU. Official Journal of the European Union, 28.12.2013. Retrieved from: http: / /eur-lex.europa.eu/LexUriServ/LexUriServ.do?uri=OJ:L: 2013:354:0132:0170:en:PDF

Eva, K. W., \& Regehr, G. (2005). Self-assessment in the health professions: A reformulation and research agenda. Academic Medicine, 80(10), S46-S54.

Eva, K. W. , \& Regehr, G. (2008). I'll never play professional football'” and other fallacies of self-assessment. Journal of Continuing Education in the Health Professions, 28(1), 14-19.

Galbraith, R. M., Hawkins, R. E., \& Holmboe, E. S. (2008). Making self-assessment more effective. Journal of Continuing Education in Health Professions, 28(1), 20-24.

Garside, J. R., \& Nhemachena, J. Z. Z. (2013). A concept analysis of competence and its transition in nursing. Nurse Education Today, 33(5), 531-545.

Gonczi, A. (1994). Competency based assessment in professions in Australia. Assessment in Education, 1, 27-44.

Hengstberger-Sims, C., Cowin, L. S., Eagar, S. C., Gregory, L., Andrew, S., \& Rolley, J. (2008). Relating new graduate nurse competence to frequency of use. Collegian: The Australian Journal of Nursing Practice, Scholarship and Research, 15(2), 69-76.

Istomina, N., Suominen, T., Razbadaukas, A., Martinkènas, A., Meretoja, R., \& Leino-Kilpi, H. (2011). Competence of nurses and factors associated with it. Medicina (Kaunas), 47(4), 230-237.

Kajander-Unkuri, S., Meretoja, R., Katajisto, J., Saarikoski, M., Salminen, L., Suhonen, R., et al. (2014). Self-assessed level of competence of graduating nursing students and factors related to it. Nurse Education Today, 34(5), 795-801.

Kajander-Unkuri, S., Suhonen, R., Katajisto, J., Meretoja, R., Saarikoski, M., Salminen, L., et al. (2014). Self-assessed level of graduating nursing students' nursing skills. Journal of Nursing Education and Practice, 4(12), 51-64.

Knowles, M. S., Holton, E. F., \& Swanson, R. A. (2008). The Adult learner. The definitive classic in adult education and human resource development. Milan, Italy: Franco Angeli Group.

Lakanmaa, R.-L., Suominen, T., Perttilä, J., Ritmala-Castrèn, M., Vahlberg, T., \& Leino-Kilpi, H. (2014). Graduating nursing students' basic competence in intensive and critical care nursing. Journal of Clinical Nursing, 23(5-6), 645-653.

Lauder, W., Holland, K., Roxburgh, M., Topping, K., Watson, R., Johnson, M., et al. (2008). Measuring competence, self-reported competence and self-efficacy in pre-registration students. Nursing Standard, 22(20), 35-43.
Levett-Jones, T. (2005). Self-directed learning: Implications and limitations for undergraduate nursing education. Nurse Education Today, 25(5), 363-368.

Lima, S., Newall, F., Kinney, S., Jordan, H. L., \& Hamilton, B. (2014). How competent are they? Graduate nurses self-assessment of competence at the start of their careers. Collegian: The Australian Journal of Nursing Practice, Scholarship and Research, 21(4), 353-358.

Löfmark, A., Smide, B., \& Wikblad, K. (2006). Competence of newly-graduated nurses - A comparison of the perceptions of qualified nurses and students. Journal of Advanced Nursing, 53(6), 721-728.

Marshburn, D. M., Engelke, M. K., \& Swanson, M. S. (2009). Relationships of new nurses' perceptions and measured performance-based clinical competence. Journal of Continuing Education in Nursing, 40(9), 426-432.

Meretoja, R., Isoaho, H., \& Leino-Kilpi, H. (2004). Nurse Competence Scale: Development and psychometric testing. Journal of Advanced Nursing, 47(2), 124-133.

Meretoja, R., Leino-Kilpi, H., \& Kaira, A.-M. (2004). Comparison of nurse competence in different hospital work environments. Journal of Nursing Management, 12(5), 329-336.

Ministry of Education. (2010). Polytecnics. Retrieved from: http://www.minedu.fi/OPM/Koulutus/ammattikorkeakoulutus/ ammattikorkeakoulut/?lang=en

Ministry of Education. (2011). Degrees of polytechnics. Retrieved from: http://www.minedu.fi/export/sites/default/ OPM/Koulutus/ammattikorkeakoulutus/opiskelu_ja_tutkinnot/ YhteenvetoKoulutusohjelmaPaatoksista_amk_2011.pdf Finnish]

Ministry of Education and Culture. (2012). Qualification of polytechnics. Retrieved from: http://vipunen.csc.fi/fi-fi/ ammattikorkeakoulutus/ammattikorkeakoulutusraportit/AMK. tutkinnot_ala.xlsx [in Finnish]

National Institute for Health and Welfare. (2012). Productivity of the hospitals. Statistical report 1/2012. Retrieved from: http://urn.fi/URN:NBN:fi-fe201205085318 [in Finnish]

Norman, I. J., Watson, R., Murrels, T., Calman, L., \& Redfern, S. (2002). The validity and reliability of methods to assess the competence to practise of pre-registration nursing and midwifery students. International Journal of Nursing Studies, 39(2), 133-145.

Numminen, O., Meretoja, R., Ihoaho, H., \& Leino-Kilpi, H. (2013). Professional competence of practicing nurses. Journal of Clinical Nursing, 22, 1411-1423.

Nursing and Midwifery Board of Australia. (2010). Continuing professional development registration standard. Retrieved from: http://www. nursingmidwiferyboard.gov.au

O'Shea, E. (2003). Self-directed learning in nurse education: a review of the literature. Journal of Advanced Nursing, 43(1), 62-70.

Pauwels, E. (2007). Ethics for researchers. Facilitating Research Excellence in FP7. Luxembourgh. Office for Official Publications of the European Communities. Retrieved from: ftp://ftp. cordis.europa.eu/pub/fp7/docs/ethics-for-researchers.pdf

Raines, D. A. (2010). Nursing practice competency of accelerated Bachelor of Science in nursing program students. Journal of Professional Nursing, 26(3), 162-167.

Ramritu, P. L., \& Barnard, A. (2001). New nurse graduates' understanding of competence. International Nursing Review, 48(1), 47-57.

Räisänen, A. (2002). Level of know-how of persons graduating nurses. Annales Universitatis Turkuensis C 178. Turku: University of Turku [in Finnish].

ten Cate, O., \& Scheele, F. (2007). Competency-based postgraduate training: can we bridge the gap between theory and clinical practice? Academic Medicine, 82(6), 542-547. 
Valvira. (2014). Professional practice rights. Retrieved from: http: / / www.valvira.fi/en/licensing/professional_practice_rights

Wangensteen, S., Johansson, I. S., \& Nordström, G. (2008). The first year as a graduate nurse - An experience of growth and development. Journal of Clinical Nursing, 17(14), 1877-1885.

Wangensteen, S., Johansson, I. S., Björkström, M. E., \& Nordström, G. (2012). Newly graduated nurses' perception of competence and possible predictors: a cross-sectional survey. Journal of Professional Nursing, 28(3), 170-181.

Watson, R., Stimpson, A., Topping, A., \& Porock, D. (2002). Clinical competence assessment in nursing: a systematic review of the literature. Journal of Advanced Nursing, 39(5), 421-431.

WHO. (2009). Nursing and midwifery/human resources for health. Geneva, Switzerland: Global Standards for the Initial
Education of Professional Nurses and Midwifes (WHO/HRH/HPN/ 08.6)

WHO. (2014). Shortage of nurses and midwives. Retrieved from: http://www.euro.who.int/en/health-topics/Health-systems/ nursing-and-midwifery/data-and-statistics

Yanhua, C., \& Watson, R. (2011). A review of clinical competence assessment in nursing. Nurse Education Today, 31(8), 832-836.

Yong, M. E., Stuenkel, D. S., \& Bawel-Brinkley, K. (2008). Strategies for easing the role transformation of graduate nurses. Journal for Nurses in Staff Development, 24(3), 105-110.

Yeh, M. C., \& Yu, S. (2009). Job stress and intention to quit in newlygraduated nurses during the first three months of work in Taiwan. Journal of Clinical Nursing, 18(24), 3450-3460. 